Proc. Indian Acad. Sci. (Chem. Sci.), Vol. 96, No. 5, March 1986, pp. 309-313.

(C) Printed in India.

\title{
Structure and stability of complexes of thiohydantoin derivative
}

\author{
R M EL-BAHNASAWY $\dagger, M$ M SHOUKRY* $¥$ and M M HUSSEIN \\ Chemistry Department, Faculty of Science, Cairo University, Cairo, Egypt \\ $\dagger$ Chemistry Department, Faculty of Science, Manoufia University, Sheben El-Kom, Egypt \\ $\ddagger$ Present address: Department of Chemistry, Faculty of Science, University of United Arab \\ Emirates, P.O box 15551, Al-Ain, United Arab Emirates.
}

MS received 22 April 1985; revised 9 September 1985

\begin{abstract}
The formation constant of 4-phenylhydrazono-2-thiohydantoin with $3 d$ transition metal ions has been determined. The factors affecting the stability of the metal chelates have been studied. Complexes of $\mathrm{Ag}(\mathrm{I}), \mathrm{Cu}(\mathrm{II}), \mathrm{Cd}(\mathrm{II})$ and $\mathrm{Pd}$ (II) with the ligand have been isolated and characterized by physico-chemical techniques. The ligand forms a $1: 1$ complex with $\mathbf{A g}(\mathrm{I})$ and $1: 2$ complexes with the other metal ions.
\end{abstract}

Keywords. 4-Phenylhydrazono-2-thiohydantoin; transition metal complexes with thiohydantoin; potentiometric studies; IR spectra.

\section{Introduction}

Many hydantoins have found use in medicine (Ware 1950) first as hypnotics, later for the treatment of chorea, and more recently in the treatment of epilepsy. A variety of hydantoin derivatives are now marketed for more than one medical purpose. However, very little work has been done on the behaviour of these compounds with transition metal ions which commonly exist in biological fluids. As part of our medicinal chemistry programme we recently synthesized new hydantoin derivatives. In this paper we report the measurements of the solution stability of $\mathrm{Pd}(\mathrm{II}), \mathrm{Cd}(\mathrm{II}), \mathrm{Zn}(\mathrm{II}), \mathrm{Co}(\mathrm{II})$, $\mathrm{Ni}(\mathrm{II})$ and $\mathrm{Ag}(\mathrm{I})$ complexes of 4-phenylhydrazono-2-thiohydantoin(I). The solid complexes of a few metal ions were isolated and characterized.<smiles>O=C1NC(=S)N/C1=N\Nc1ccccc1</smiles>

(I)

\section{Experimental}

\subsection{Materials}

Solutions of $\mathrm{Pd}(\mathrm{II}), \mathrm{Cd}(\mathrm{II}), \mathrm{Co}(\mathrm{II}), \mathrm{Zn}(\mathrm{II}), \mathrm{Ni}(\mathrm{II})$ and $\mathrm{Ag}(\mathrm{I})$ were prepared in double distilled water from analytical grade palladium chloride, cadmium nitrate, zinc nitrate,

* To whom all correspondence should be addressed. 
cobalt chloride, nickel chloride and silver nitrate. All solutions were standardized by established procedures (Welcher 1965).

4-phenylhydrazono 2-thiohydantoin(I) was prepared as per Baranov and Perova (1968). All the metal complexes except $\mathrm{Ag}(\mathrm{I})$ complex were prepared by mixing $2 \mathrm{~m} \mathrm{~mol}$ of the organic ligand(I) with $1 \mathrm{~m}$ mole of the metal ion, both dissolved in the minimum volume of ethanol. Dilute $\mathrm{NaOH}$ was slowly added with stirring to adjust the $\mathrm{pH}$ of the solution to 7-8, at which the metal chelates precipitate. The complexes were filtered from the solution and then washed thoroughly with an ethanol-water mixture $(1: 1)$. The $\mathbf{A g}(\mathbf{I})$ complex was prepared using the ratio $1: 1$ (Ag:ligand).

EXTECH, model 671 digital pH-meter was used for pH measurements. The $\mathrm{pH}$ measurements are devoid of errors arising from solvent and ionic strength of the medium. For this purpose, readings were made on a series of solutions containing known amounts of $\mathrm{HCl}$ and $\mathrm{NaCl}$ such that $\mu$ was $0.1 \mathrm{M}$. The value of $\log U_{\mathrm{H}}$ in $70 \%$ EtOH-water solutions and ionic strength $0.1 \mathrm{M}$, at $25^{\circ} \mathrm{C}$, was found to be -0.25 (Van Uitert and Hass 1953). The IR spectra were recorded (KBr) on a Perkin-Elmer 598 infrared spectrophotometer.

The formation constant determinations were carried out using the following mixtures:

(i) $5 \mathrm{ml}$ of $1 \mathrm{M}$ sodium chloride $+1 \mathrm{ml}$ of $0.1 \mathrm{M} \mathrm{HCl}$

(ii) Mixture (i) $+20 \mathrm{ml}$ of $2.5 \times 10^{-3} \mathrm{M}$ ligand

(iii) Mixture (ii) $+1 \mathrm{ml}$ of $0.01 \mathrm{M}$ metal ion solution.

The total volume of each mixture was made up to $50 \mathrm{ml}$ and at the same time contained $70 \%$ in ethanol and had an ionic strength of $0.1 \mathrm{M}$ sodium chloride. The mixtures (40 ml) were separately titrated with a carbonate free $0.05 \mathrm{M} \mathrm{NaOH}$ solution. In the case of the $\mathrm{Ag}(\mathrm{I})$ complex, the system did not contain $\mathrm{HCl}$ solution. The titrations were performed under a purified nitrogen atmosphere and at $25^{\circ} \mathrm{C}$. From $\mathrm{pH}$ titration curves, the values of $\bar{n}_{A}, \bar{n}$, and $p L$ were calculated as previously reported (Nayan and Dey 1972).

\section{Results and discussion}

Proton-ligand system: The protonation constant of the thiohydantoin derivative is calculated from the potentiometric titration curves with acid in the presence and the absence of ligand. The formation curve, figure 1, for the proton ligand system was extended between 0 and 1 in the $\bar{n}_{A}$ scale and it indicated that the ligand has one dissociable proton. The protonation constant $\log K_{1}^{\mathrm{H}}$ was read directly from the graph. Also, $\log K_{1}^{\mathrm{H}}$ was calculated by the average value method (Nayan and Dey 1972). Proton release is enhanced by the stability of the conjugate base in which the negative charge can be localised on $\mathrm{S}, \mathrm{N}$ and $\mathrm{O}$ atoms as shown:

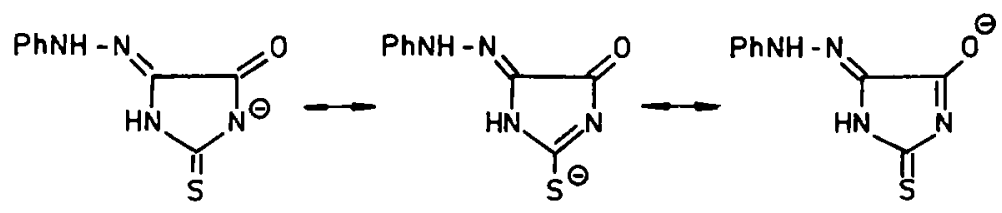




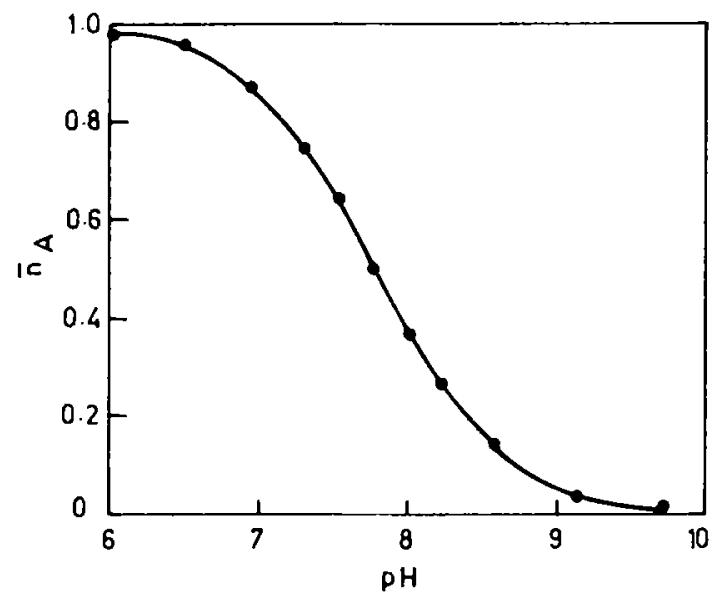

Figure 1. Formation curve for proton-ligand complex of thiohydantoin derivative.

Metal-ligand system: The respective metal ions with the ligand were titrated against $\mathrm{NaOH}$. The metal complex and ligand titration curves are well separated, indicating the liberation of protons due to complexation.

Values of $\bar{n}$ and $p L$ were obtained from previous equations (Nayan and Dey 1972).

$$
\begin{aligned}
\bar{n} & =\left[\left(V^{\prime \prime \prime}-V^{\prime \prime}\right)\left(N^{0}+E^{0}\right)\right] /\left[\left(V^{0}+V^{\prime}\right) T_{C M}^{0} \bar{n}_{\mathrm{H}}\right], \\
p L & =\log \left\{\beta_{n}^{\mathrm{H}}\left[\mathrm{H}^{+}\right]^{n}\left(V^{0}+V^{\prime \prime \prime}\right)\right\} /\left\{\left(T_{C L}^{0}-\bar{n} T_{C M}^{0}\right) V^{0}\right\},
\end{aligned}
$$

where $V^{\prime}, V^{\prime \prime}$ and $V^{\prime \prime \prime}$ denote the volume of alkali required to reach the same $\mathrm{pH}$ in the titrations of mixture (i), (ii) and (iii) respectively; $V^{0}$ the initial volume of the titrated solution; $N^{0}$ the normality of alkali; $E^{0}$ the initial concentration of the free acid; $T_{C M}^{0}$ the total metal ion concentration, $T_{C L}^{0}$ the total ligand concentration; and $B_{n}^{\mathrm{H}}$ the overall proton ligand formation constant value. The graphs of $\bar{n}$ vs. $p L$, were plotted and are given in figure 2 .

The formation curves for metal-ligand complexes show that for $\mathrm{Ag}(\mathrm{I})$, the $\bar{n}$ values attain a maximum value of 1 , but with othe metal ions, it approaches two, thus indicating that with $\mathrm{Ag}(\mathrm{I})$ only one complex $M L$ is formed, whereas in other cases two complexes $M L$ and $M L_{2}$ are formed stepwise. The values of $\log K_{1}$ and $\log K_{2}$ were calculated as previously reported (Nayan and Dey 1972).

The tendency of the metal ion to take up a ligand is proportional to its coordination number. The coordination positions are more freely available for the bonding of the first ligand to a given metal ion than for the second ligand. As such the $\log K_{1}-\log K_{2}$ value is usually positive, based on statistical grounds. In the present study, this value lies within 0.7 to $1.4 \log K$ units.

It can be seen from the results given in table 1 , that $\log K_{1}$ runs in the order,

$$
\operatorname{Ag}(\mathrm{I})<\mathrm{Co}(\mathrm{II})<\mathrm{Zn}(\mathrm{II})<\mathrm{Ni}(\mathrm{II})<\mathrm{Cd}(\mathrm{II})<\mathrm{Pd}(\mathrm{II}) .
$$

The analytical data of the solid complexes, given in table 2, show that the $\operatorname{Ag}(\mathbf{I})$ complex has $1: 1$ stoichiometry and the other metal complexes have $1: 2$ stoichiometry.

The IR spectrum of the ligand under investigation show bands occurring at 3170 , 


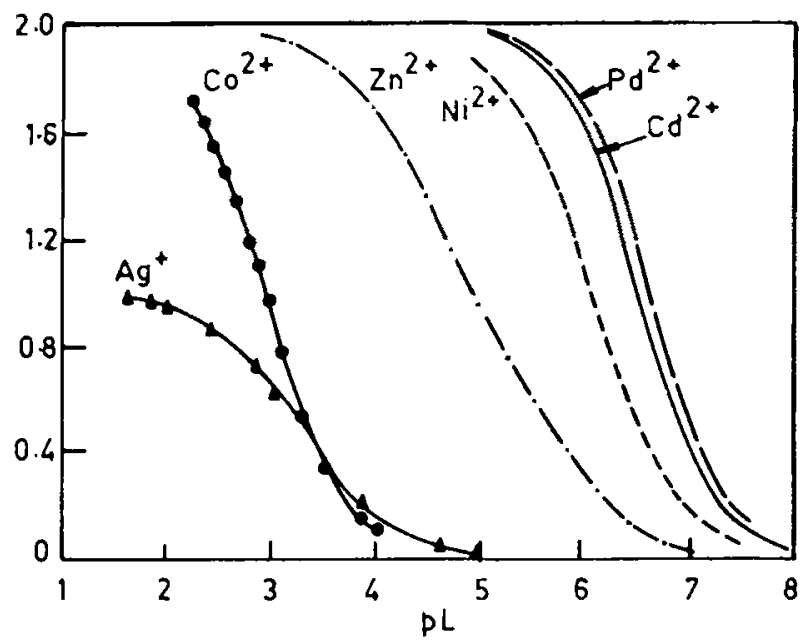

Figure 2. Formation curves for metal complexes of thiohydantoin derivative.

Table 1. Formation constants of some metal ion complexes of the thiohydantoin derivative.

\begin{tabular}{lccc}
\hline Metal ion & $\log K_{1}$ & $\log K_{2}$ & $\log \beta_{2}$ \\
\hline H $^{+}$ & 7.65 & - & - \\
Pd(II) & 7.00 & 6.25 & 13.25 \\
Cd(II) & 6.90 & 6.15 & 13.05 \\
Zn(II) & 5.75 & 4.35 & 10.10 \\
Co(II) & 3.35 & 2.55 & 5.90 \\
Ni(II) & 6.55 & 5.65 & 12.20 \\
Ag(I) & 3.32 & - & - \\
\hline
\end{tabular}

Table 2. Analytical data* of the metal complexes of the thiohydantoin derivative.

\begin{tabular}{lccccc}
\hline Compound & $\mathrm{C} \%$ & $\mathrm{H} \%$ & $\mathrm{~N} \%$ & $\mathrm{~S} \%$ & $M \%$ \\
\hline $\mathrm{Ag}\left(\mathrm{C}_{9} \mathrm{H}_{7} \mathrm{~N}_{4} \mathrm{SO}\right)$ & $33 \cdot 1$ & $2 \cdot 2$ & $16 \cdot 3$ & $9 \cdot 0$ & $31 \cdot 9$ \\
& $(33 \cdot 0)$ & $(2 \cdot 2)$ & $(17 \cdot 1)$ & $(9-8)$ & $(32 \cdot 7)$ \\
$\mathrm{Cd}\left(\mathrm{C}_{9} \mathrm{H}_{7} \mathrm{~N}_{4} \mathrm{SO}\right)_{2}$ & $38 \cdot 9$ & $2 \cdot 6$ & $19 \cdot 5$ & $10 \cdot 7$ & $21 \cdot 4$ \\
& $(39 \cdot 2)$ & $(2 \cdot 6)$ & $(20-3)$ & $(11 \cdot 6)$ & $(20 \cdot 4)$ \\
$\mathrm{Cu}\left(\mathrm{C}_{9} \mathrm{H}_{7} \mathrm{~N}_{4} \mathrm{SO}\right)_{2} \cdot 4 \mathrm{H}_{2} \mathrm{O}$ & $37 \cdot 7$ & $3 \cdot 9$ & $18 \cdot 8$ & $10 \cdot 3$ & $10 \cdot 9$ \\
& $(37 \cdot 6)$ & $(3 \cdot 8)$ & $(19 \cdot 5)$ & $(11 \cdot 2)$ & $(11 \cdot 1)$ \\
$\mathrm{Pd}\left(\mathrm{C}_{9} \mathrm{H}_{7} \mathrm{~N}_{4} \mathrm{SO}\right)_{2} \cdot 3 \mathrm{H}_{2} \mathrm{O}$ & $30 \cdot 3$ & $3 \cdot 0$ & $15 \cdot 2$ & $10 \cdot 1$ & $14 \cdot 3$ \\
& $(30.9)$ & $(2 \cdot 9)$ & $(16 \cdot 0)$ & $(9 \cdot 2)$ & $(15 \cdot 2)$ \\
\hline
\end{tabular}

- Calculated values in parentheses. 
1700 and $1610 \mathrm{~cm}^{-1}$. These bands may be due to $\mathrm{NH}, \mathrm{C}=\mathrm{O}$ and $\mathrm{C}=\mathrm{N}$ stretching, respectively (Bellamy 1966). The ligand studied has a thione group $(\mathrm{C}=\mathrm{S})$ and protons adjacent to the thione group. It has been stated that the thione group $(\mathrm{C}=\mathrm{S})$ is relatively unstable in the monomeric form and tends to turn to a stable $=\mathrm{C}-\mathrm{SH}$ group, if there is at least one hydrogen atom adjacent to the $\mathrm{C}=\mathrm{S}$ bond (Mayer 1967). The IR spectrum of the ligand does not display the (S-H) band at $2570 \mathrm{~cm}^{-1}$ indicating that, at least in the solid state it remains in the thione form. A medium band at $1370 \mathrm{~cm}^{-1}$ in the IR spectrum of the ligand is tentatively assigned as the $C=S$ stretch (Bellamy 1966). Most of the thioureas previously investigated showed a band for the $\mathrm{C}=\mathrm{S}$ group, occurring in the range $1400-1500 \mathrm{~cm}^{-1}$. This wide range was attributed to varying degrees of coupling as reported by Bellamy.

The IR spectra of $\mathrm{Cu}(\mathrm{II}), \mathrm{Cd}(\mathrm{II})$ and $\mathrm{Ag}$ (I) complexes show the disappearance of the $\mathrm{NH}$ band. Also, the $\mathrm{C}=\mathrm{O}$ and $\mathrm{C}=\mathrm{N}$ absorption bands are red shifted to $\approx 1660 \mathrm{~cm}^{-1}$ and $\approx 1580 \mathrm{~cm}^{-1}$ respectively. Based on these observations, the complex formation reaction is assumed to occur by the release of a hydrogen ion and participation of carbonyl oxygen together with the $\mathrm{C}=\mathbf{N}$ group in the formation of a stable fivemembered ring as shown in the following. The IR spectrum of the $\mathrm{Cu}$ (II) complex shows a broad band occurring at $3450 \mathrm{~cm}^{-1}$ which might be due to water molecules.<smiles></smiles>

The IR spectrum of the Pd(II) complex shows the disappearance of $v(\mathrm{NH})$ and $v(\mathrm{C}=\mathrm{S})$ bands and a blue shift of the carbonyl band to $1720 \mathrm{~cm}^{-1}$. This is explained by the participation of the S-atom and the release of $\mathrm{H}^{+}$. The carbonyl oxygen is not involved in complexation.

\section{References}

Baranov S N and Perova T V 1967 Khim. Geterotsikl. Soedin 326; 1968 Chem. Abstr. $682855 K$

Bellamy L J 1966 The infrared spectra of complex molecules (New York: John Wiley \& Sons) p. 356

Mayer R 1967 Organosulphur chemistry (ed.) M Z Wansen (New York: Interscience)

Nayan R and Dey A K 1972 Indian J. Chem. 10109

Van Uitert L G and Hass C G $1953 \mathrm{~J}$. Am. Chem. Soc. 75451

Ware E 1950 Chem. Rev. 46453

Welcher F J 1965 The analytical uses of ethylenediaminetetraacetic acid (Princeton, New York: Van Nostrand) 